\title{
Origin and Distribution of the Lumbosacral Plexus Anatomy in Van Cats
}

\author{
Origen y Distribución de la Anatomía del Plexo Lumbosacro en Gatos Van
}

\author{
Ismail Hakkı Nur'; William Pérez²; Horst-Erich König ${ }^{3}$ \& Andrea Linton ${ }^{4}$
}

NUR, I. H.; PÉREZ, W.; KÖNIG, H. E. \& LINTON, A. Origin and distribution of the lumbosacral plexus anatomy in Van cats. Int. J. Morphol., 39(3):848-857, 2021.

SUMMARY: The innervation of the pelvic limbs of the Van cat is investigated in this research. The origins of the nerves, the innervated muscles and nerve diameters were shown in a table. Five cat cadavers were used in the study. The pudendal nerve originated from the S1-S2 spinal nerves. The femoral nerve consisted of the ventral branches of the 5th and 6th lumbar nerves in 4 cats The ischiatic nerve was composed of the 6th and 7th lumbar (L6-L7) and S1 spinal nerves in all cadavers. The ischiatic nerve was the thickest branch of sacral plexus (the average diameter on the right side was $3.31 \pm 0.27 \mathrm{~mm}$ and the average diameter on the left side was $3.28 \pm 0.29 \mathrm{~mm}$ ). The lumbosacral plexus was formed by the ventral branches of the L4-S3 spinal nerves. N.genitofemoralis consisted of only the ventral branches of L4 in all cadavers. N. femoralis did not give rise to a branch to the m. iliopsoas. N.plantaris lateralis was found to give a branch to the 3 th finger. The quadriceps femoris muscles did not take any branches from either the ischiadicus nerve or the pudendal nerve. The obturator nerve did not receive any branches from the L4 spinal nerves. There was no branch to the skin from the caudal gluteal nerve. The thinnest nerve was the pudendal nerve. Due to the scarcity of studies on the lumbosacral plexus of cats, it is thought that this study will complete a gap in the field of veterinary anatomy.

KEY WORDS: Felidae; Lumbosacral plexus; Peripherical nervous system; Pelvic limb.

\section{INTRODUCTION}

Van cats are a protected endemic species found in the Lake Van region of Turkey. Special permission is required to purchase this expensive and economically valuable cat from Turkey. Van cats have white fur, triangular heads, moderately long bodies, and upright ears with a pinkish interior (Cak, 2017). They have an affinity for swimming and are characterized by their eye color: both eyes amber, both eyes blue, or one amber and one blue eye (Ates, 2000; Cak). Newborn Van cats have grayish eyes that begin to differentiate in color 25 days after birth, becoming clearer after 40 days. In cats with both an amber and a blue eye, deafness is observed in the ear on the side with the blue eye, which increases the probability of accidents, injury, and disability. The rate of Van cats presenting with paraplegia, pelvic fractures, or femoral fractures has been high in the Veterinary Faculty clinics at Van Yüzüncü Yıl University, possibly due to hearing loss. The ischiatic and fibular nerves are principally involved in traumatic nerve injuries of the hindlimb (Bennett \& Vaughan, 1976). Injury to the ischiatic nerve is especially seen in sacroiliac dislocations and fractures of the sacral wing, the caudal acetabulum, and the ischium (Curtis \& da Costa, 2015). These fractures and injuries to the ischiatic nerve cause some sensory loss in the lower limbs, but sensory loss can also be caused by tumors on the peripheral nerves or other peripheral nerve disorders.

It is important to understand the anatomy of Van cats to facilitate treatment of injury, disease, and to assist with veterinary anesthesia. Regional anesthesia and nerve blocks are widely used in human anesthesia to reduce the need for and associated risk with general anesthesia, to improve postoperative analgesia, and to increase patient comfort in the postoperative period (Roberts, 2006). Recent studies in veterinary anesthesia report using surface anatomical points to make these peripheral nerve blocks (Müller, 1986; Rasmussen et al., 2006; Lamont \& Lemke, 2008; Gurney \& Leece, 2014). Few studies exist that describe the anatomy of Van cats (Nur \& Ar1, 2000; Nur et al., 2020).

\footnotetext{
${ }^{1}$ Department of Anatomy, Faculty of Veterinary Medicine, Erciyes University, Kayseri, Turkey.

${ }^{2}$ Unidad de Anatomía, Facultad de Veterinaria, Universidad de la República, Montevideo, Uruguay.

${ }^{3}$ Institut für Anatomie, Histologie und Embryologie, Veterinärmedizinische Universität, Wien, Österreich.

${ }^{4}$ Department of Biomedical Sciences at Colorado State University, W103 Anatomy/Zoology, BMS-Anatomy, CSU, 1617 Campus Delivery, Fort Collins, CO, 80523-1617, USA.
} 
Both the anatomy of the ischiatic nerve and the formation and location of the lumbosacral plexus were examined in this study because of their importance in traumatic neuropathies and pelvic fractures in dogs and cats. According to Maierl \& Liebich (1998), the development of the spinal cord in cats is reported to begin immediately after birth and is completed after 5 to 6 months. Maierl \& Liebich found that some segments of cats had descensus; for example, the 13th thoracic segment is located at the level of the L1st vertebra. The lumbosacral plexus gives origin to the nerves of the pelvic limb and is an enhancement of the continuous plexus. It usually begins with the ventral ramus of the L4th and the S2th nerves (Dyce et al., 2000). According to Ghoshal (1972), the lumbosacral plexus of the cat is formed by the ventral branches of the last L4th and S1st nerves. According to Dursun (2000), the lumbosacral plexus of the carnivore is formed by the ventral branches of the last three lumbar and sacral (S1-S3) nerves.

This study aims to document the innervation of the pelvic limbs of the Van cat, including the origin of the nerves, the innervated muscles, and nerve diameters by dissection.

\section{MATERIAL AND METHOD}

In this research, five female cadavers van cats were used. The cats were 2 to 3 years old. The average weight of the cats was $2.5 \mathrm{~kg}$ to $3.0 \mathrm{~kg}$. The cadavers were donated to the Veterinary Faculty clinics at Van Yüzüncü Yıl University for various reasons. All animals died of natural causes were delivered to the Department of Anatomy for use in this study. The animals did not present signs of muscular disorders related to the pelvic limb. Before conducting this study, the cadavers were kept in a $10 \%$ formaldehyde solution for about 12 months. The dissection was photographed with a camera (Samsung NX300-Japan, 20. 3 Mp) and a Zoom Stereo Microscope (Olympus SZ-PT- Japan-Auxiliary objective 100ALO 0,5X, eyepiece GSWH 10X/22 ) was used. For the terminology was used Nomina Anatomica Veterinaria (International Committee on Veterinary Gross Anatomical Nomenclature, 2017). This experimental study was approved on August 29, 2019 (approval code 19/155) by the Committee for Ethics of Animal Research (ERÜHADYEK) at Erciyes University, Kayseri, Turkey.

\section{RESULTS}

The lumbosacral plexus comprised the lumbar plexus, derived from ventral branches of the L4, L5, L6 and L7 roots, and the sacral plexus, arising from the $\mathrm{S} 1, \mathrm{~S} 2$ and $\mathrm{S} 3$ roots (Fig. 1). The lumbar plexus was a nerve network in the lumbar region, passing between the psoas muscles and located in the ventral of the processes transverse of the lumbar vertebrae. The sacral plexus was located on the ventral surface of the piriformis muscle. It emerged from the caudal part of the medulla spinalis. The rami dorsales left the canalis vertebralis from the foramina sacralia dorsalia. The dorsal branches were weaker than the ventral branches. The medial branches of rami dorsales innervated the $\mathrm{mm}$. multifidi and the dorsal aspect of the tail. The rami ventrales of nervi sacrales left the canalis vertebralis through the foramina sacralia ventralia of the sacrum. The ventral branches of the last lumbar nerve and the ventral branches of the first two to three sacral nerves united to form the plexus sacralis. The ventral branches of the first two sacral nerves were readily visible, and the last sacral nerve was fragile.

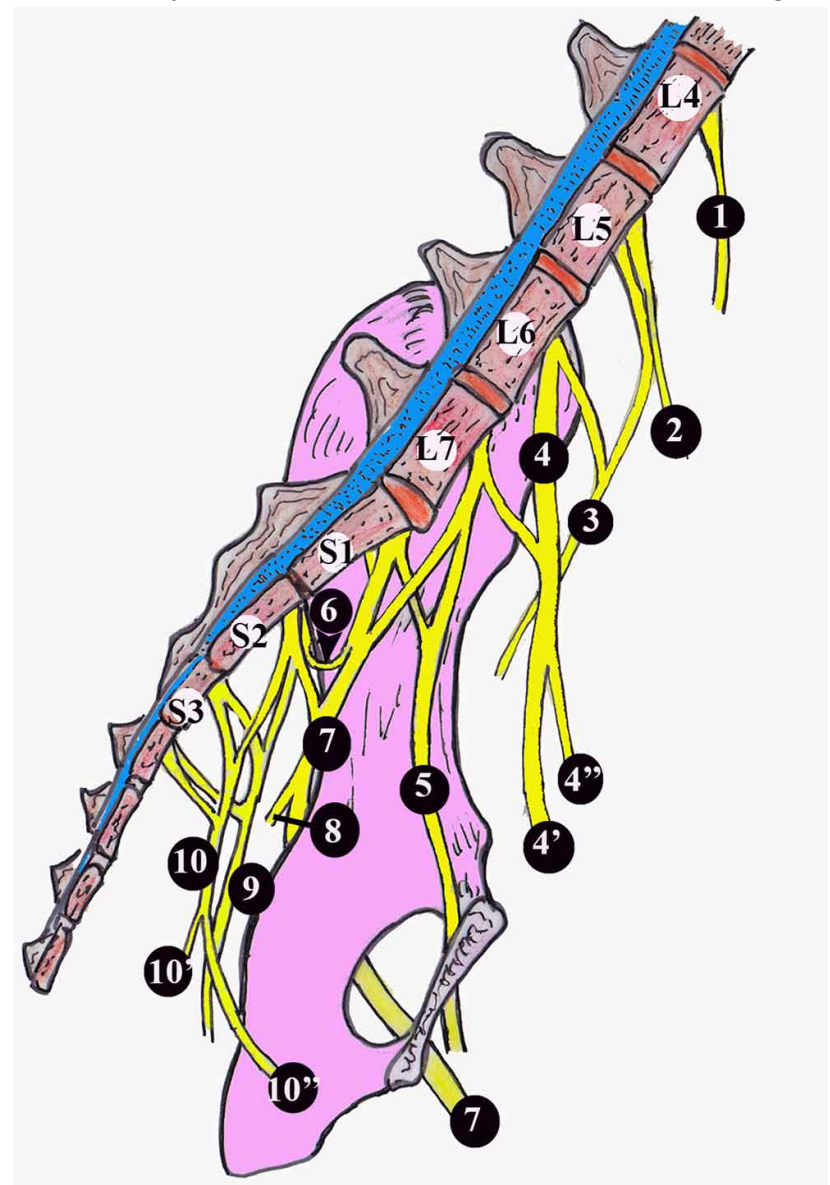

Fig. 1. Schematic illustration of lumbosacral plexus, medial view in the Van cat. 1.N.ilioinguinalis; 2.N.gentiofemoralis; 3.N.cutaneus femoris lateralis; 4. and 4'.N.femoralis; 4".N.saphenus; 5. N.obturatorius; 6. (black arrow) N.gluteus cranialis; 7. N.ischiadicus; 8. N.gluteus caudalis; 9.N.pudendus; 10. Nn. rectales caudales; 10 '. Branch of on the lateral surface of rectum; 10". The branch of vesica urinaria and perineal region. (99 x $143 \mathrm{~mm} 300$ DPI) 
Schematic illustration of lumbosacral plexus, medial view (Fig. 1), origin and innervated muscles of the lumbosacral plexus (Table I), and diameters of the nerves were given in Table II.

N. iliohypogastricus. was formed by the ventral branches of the first two lumbar nerves under the peritoneum between the mm. psoas major and quadratus lumborum. The $\mathrm{N}$. iliohypogastricus cranialis originated from from the L1 nerve, the $\mathrm{N}$. iliohypogastricus caudalis from the $\mathrm{L} 2$ nerve. The diameter of the iliohypogastric nerve was $0.63 \pm 0.15$ $\mathrm{mm}$ on the right side and $0.65 \pm 0.20 \mathrm{~mm}$ on the left side. It divided into a medial and lateral branch. Soon after exiting underneath the peritoneum, the iliohypogastric nerve divided into the deep medial ramus, which continued in the inguinal region and the lateral ramus. The lateral branch gave rise to smaller branches that innervated the $\mathrm{m}$. transversus abdominis and the $\mathrm{m}$. obliquus internus abdominis, but it primarily innervated the $\mathrm{m}$. obliquus externus abdominis, the mammary glands, and the medial aspect of the thigh. The ramus lateralis bifurcated into the ramus cutaneus lateralis and ventralis. The ramus cutaneus lateralis innervated a narrow area of skin over the flank region to the craniolateral surface of the knee joint. The ramus cutaneus ventralis ran ventrally between the deeper abdominal muscles and their aponeuroses, and then it innervated the ventral abdominal skin, the mammary gland, and the skin on the medial surface of the thigh.

Table I. Origins of the nerves, which comprise the lumbosacral plexus in Van cats.

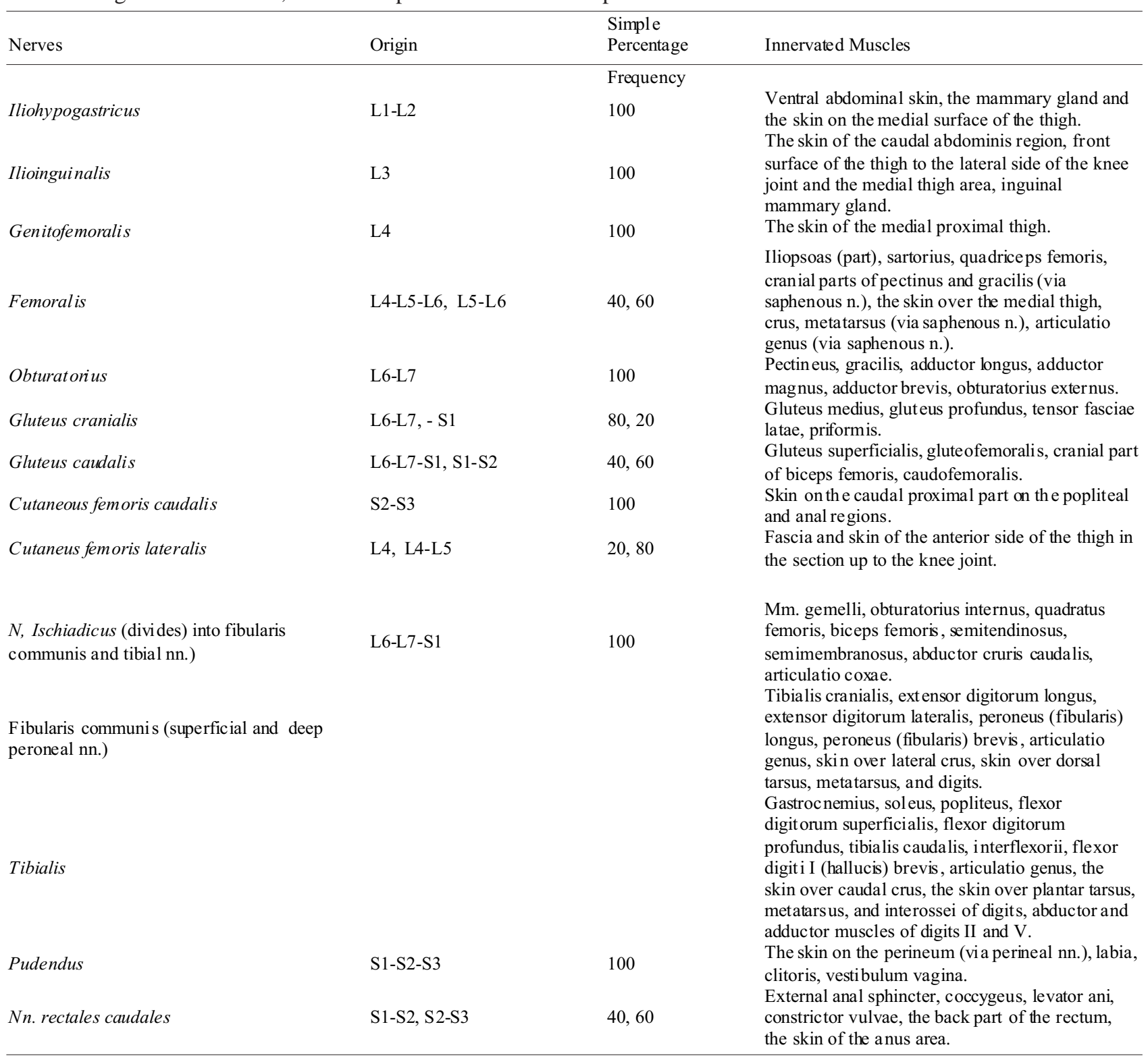


Table II. Diameters of nerves of the lumbosacral plexus in the Van cat.

\begin{tabular}{lcc}
\hline Nerve & $\begin{array}{c}\text { Diameter } \\
\text { (left) and SD }\end{array}$ & $\begin{array}{c}\text { Diameter } \\
\text { (Right) and SD }\end{array}$ \\
\hline Iliohypogastricus & $0.65 \pm 0.20 \mathrm{~mm}$ & $0.63 \pm 0.15 \mathrm{~mm}$ \\
Ilioinguinalis & $0.59 \pm 0.19 \mathrm{~mm}$ & $0.55 \pm 0.20 \mathrm{~mm}$ \\
Genitofemoralis & $0.61 \pm 0.15 \mathrm{~mm}$ & $0.60 \pm 0.17 \mathrm{~mm}$ \\
Cutaneus femoris lateralis & $0.52 \pm 0.15 \mathrm{~mm}$ & $0.52 \pm 0.15 \mathrm{~mm}$ \\
Femoral is & $2.07 \pm 0.15 \mathrm{~mm}$ & $2.10 \pm 0.10 \mathrm{~mm}$ \\
Obturatorius & $0.71 \pm 0.23 \mathrm{~mm}$ & $0.75 \pm 0.15 \mathrm{~mm}$ \\
Gluteus cranialis & $0.52 \pm 0.15 \mathrm{~mm}$ & $0.51 \pm 0.18 \mathrm{~mm}$ \\
Gluteus caudalis & $0.43 \pm 0.25 \mathrm{~mm}$ & $0.47 \pm 0.25 \mathrm{~mm}$ \\
Cutaneus femoris caudalis & $0.45 \pm 0.24 \mathrm{~mm}$ & $0.47 \pm 0.12 \mathrm{~mm}$ \\
Ischiadicus (divides into fibularis communis and tibial & $3.28 \pm 0.29 \mathrm{~mm}$ & $3.31 \pm 0.27 \mathrm{~mm}$ \\
Fibularis communis (superficial and deep peroneal nn.) & $1.20 \pm 0.23 \mathrm{~mm}$ & $1.25 \pm 0.12 \mathrm{~mm}$ \\
Tibialis & $1.90 \pm 0.12 \mathrm{~mm}$ & $1.85 \pm 0.12 \mathrm{~mm}$ \\
Pudendus & $0.37 \pm 0.19 \mathrm{~mm}$ & $0.41 \pm 0.10 \mathrm{~mm}$ \\
Rectales caudales & $0.55 \pm 0.05 \mathrm{~mm}$ & $0.57 \pm 0.11 \mathrm{~mm}$ \\
\hline
\end{tabular}

N. ilioinguinalis (Fig. 1) was predominantly not a plexus nerve. It formed the continuation of the ventral branch of the L3 nerve and later became the iliohypogastric nerve. On the right side, the average diameter was $0.55 \pm 0.20 \mathrm{~mm}$, and on the left side the average diameter was $0.59 \pm 0.19$ $\mathrm{mm}$. It divided into lateral and medial branches. The lateral branch innervated the obliquus internus, externus abdominis, and the rectus abdominis muscles. The medial branch innervated the skin of the caudal abdominis region and the medial thigh region at the level of the 7th lumbar vertebra.

N. genitofemoralis (Fig. 1) originated from the fourth lumbar nerve. On the right side, the average diameter was 0.60 $\pm 0.17 \mathrm{~mm}$, and on the left side was $0.61 \pm 0.15 \mathrm{~mm}$. It divided into the $\mathrm{N}$. cutaneus femoris lateralis, the $\mathrm{N}$. genitofemoralis, and a ramuscommunicans to the ventral branch of the L5 nerve. In two cases, a thin ramus muscularis nerve innervated the $\mathrm{m}$. obliquus internus abdominis. The N. genitofemoralis innervated the skin of the pubic region, the caudal abdominal wall, and the craniomedial side of the thigh.

N. cutaneus femoris lateralis (Fig. 2a) originated from the ventral branch of the L4 nerve in one cat, and the L4 and L5 nerves in the other four Van cats. On the right side, the average diameter was $0.52 \pm 0.15 \mathrm{~mm}$, and on the left side the average diameter was $0.52 \pm 0.15 \mathrm{~mm}$. It passed between the mm. psoas major and psoas minor. It was parallel to the m. tensor fasciae latae. It terminated in the fascia and skin of the anterior side of the thigh to the knee joint.
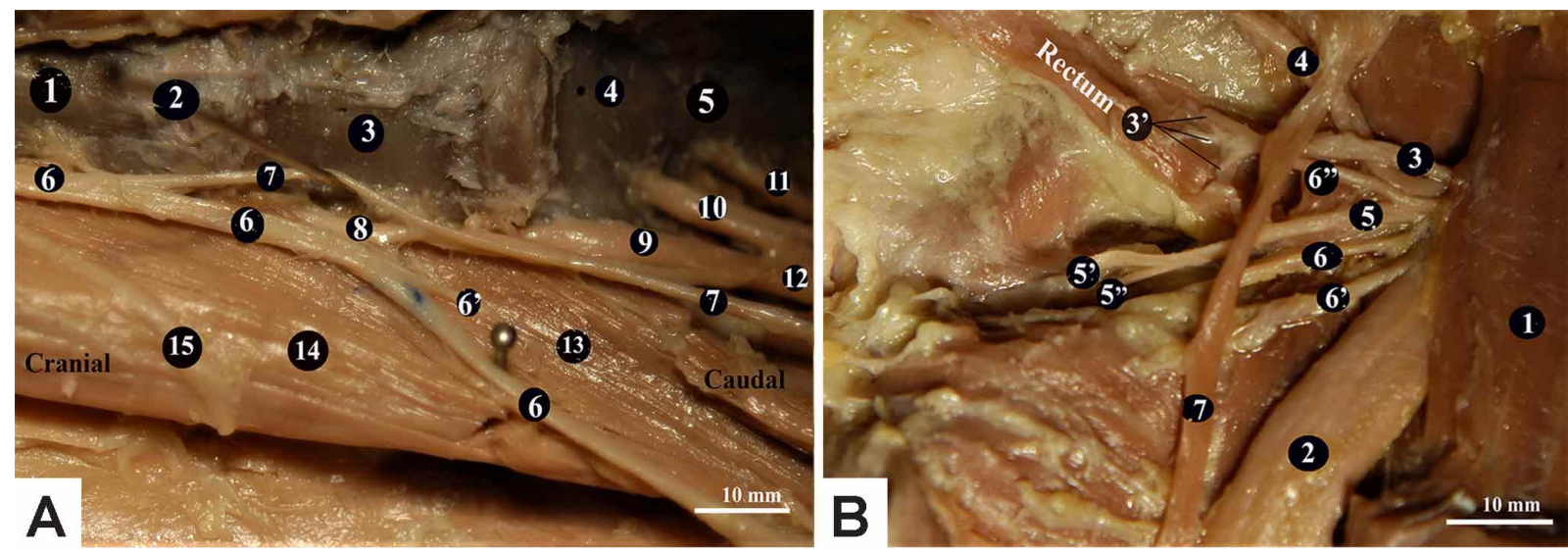

Fig. 2. Lumbosacral plexus of the right pelvic limb of the Van cat; ventral view of the abdominis region, right recumbency. A. Lumbosacral plexus of the right pelvic limb of the cat; ventral view of the abdominis region, right recumbency. 1. L5th vertebrae; 2. L6th vertebrae; 3. L7th vertebrae; 4. S1st vertebrae; 5. S2th vertebrae; 6. N.femoralis; 6'. The muscular branch of N. femoralis; 7. N. obturatorius; 8. The ventral branch of L6th spinal nerve; 9. The ventral branch of L7th spinal nerve; 10 . The ventral branch of S1 nerve; 11. The ventral branch of S2 nerve; 12. N.ischiadicus; 13. M. psoas minor; 14. M. psoas major; 15. N. cutaneus femoris lateralis. B. Right gluteal region of the cat, lateral view. 1.M. gluteus profundus; 2. N.ischiadicus; 3. N.rectales caudales; 3'. The terminal branches of Nn. rectales caudales; 5 . N.pudendus; 5'. The superficial branch of N.pudendus; 5'. The deep branch of N.pudendus; 6. 6', and 6"' N. gluteus caudalis and its muscular branches; 7. M. abductor cruris caudalis (160 x 56 mm 300 DPI). 
N. femoralis (Fig. 2a) was larger than the lateral cutaneous femoral nerv and was formed by contributions from the L5th and L6th nerves in 4 cats. The other two cats consisted of the ventral branches of the L4th, L5th and L6th spinal nerves. On the right side, the average diameter was $2.10 \pm 0.10 \mathrm{~mm}$, and on the left side the average diameter was $2.07 \pm 0.15$ $\mathrm{mm}$. This nerve were lying on the ventral surface of the psoas minör, iliopsoas muscles. It divided into three or four branches. Shortly after the beginning of the femoris nerve, it gave rise to a strong branch to the $\mathrm{m}$. psoas minor and continued cranioventrally. One branch went to the $m$. sartorius, and two went between the $\mathrm{mm}$. rectus femoris and vastus medialis. It then gave rise to branches that innervated the mm. sartorius, articularis coxae, quadriceps femoris, pectineus and gracilis in addition to the muscles above.

After leaving the saphenus nerve, the craniolateral femoral nerve left the abdominal cavity. The saphenous nerve ran distally, accompanying the femoral artery and the saphenous artery. The saphenous nerve gave rise to branches to the $\mathrm{mm}$. sartorius, pectineus, and gracilis. The cutaneous branches of the saphenous nerve terminated in the skin on the medial side of the thigh, knee, leg, tarsus, and hind paw.

N. obturatorius (Fig. 2a) is formed by the ventral branches of the L6 and L7 nerves. On the right side, the average diameter was $0.75 \pm 0.15 \mathrm{~mm}$, and on the left side the average diameter was $0.71 \pm 0.23 \mathrm{~mm}$. It ran caudoventrally and passed through the cranial part of the foramen obturator. The obturator nerve innervated the $\mathrm{mm}$. obturatorius externus, pectineus, gracilis, and adductor.
N. gluteus cranialis (Fig. 3a) derived from the L6, L7, and S1 nerve in one cat and from the L6 and L7 nerves in four cats. On the right side, the average diameter was $0.51 \pm 0.18$ $\mathrm{mm}$, and on the left side the average diameter was $0.52 \pm$ $0.15 \mathrm{~mm}$.

After it separated from the lumbosacral plexus, it passed from the incisura ischiadica major. Here it innervated the gluteus medius (including its accessory head), gluteus profundus, piriformis, and tensor fasciae latae muscles.

N. gluteus caudalis (Figs. 2b, 3a) was formed by the ventral branches of the L6, L7, and S1 in two Van cats, and S1 and S2 in three Van cats. On the right side, the average diameter was $0.47 \pm 0.25 \mathrm{~mm}$, and on the left side the average diameter was $0.43 \pm 0.25 \mathrm{~mm}$.

It had no cutaneous branches and passed by the lateral surface of the ilium through the incisura ischiadica major and innervated the gluteus superficialis, gluteus femoris, and the cranial part of the biceps femoris muscles.

N. ischiadicus (Figs. 2-3) originated from ventral branches of the L6, L7, and S1 spinal nerves. On the right side, the average diameter was $3.31 \pm 0.27 \mathrm{~mm}$, and on the left side the average diameter was $3.28 \pm 0.29 \mathrm{~mm}$. The ischiatic nerve left the pelvic cavity by crossing through the incisura ischiadica major. While coursing underneath the $\mathrm{m}$. piriformis, the ischiatic nerve gave rise to branches to the gemelli and quadratus femoris muscles. The $\mathrm{N}$. ischiadicus nerve continued caudally and gave off a large muscular
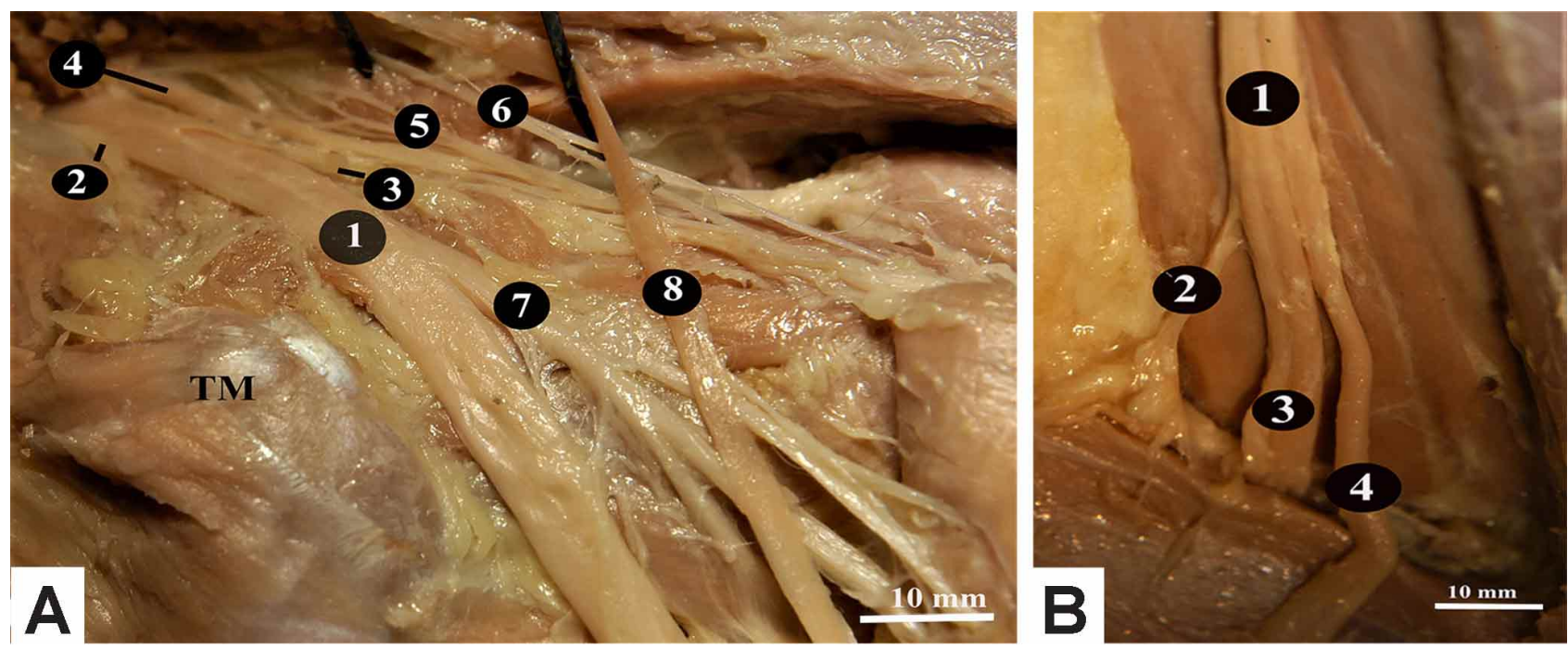

Fig. 3. A. Left gluteal region of the cat, lateral view. TM. Trochanter major; 1. N.ischiadicus; 2. N.gluteus cranialis; 3. N. gluteus caudalis; 4. N.pudendus; 5. Nn. rectales caudales; 6. N. cutaneus femoris caudalis; 7. Muscular branches of the ischiatic nerve; 8. M. abductor cruris caudalis. B. Lateral view of the right pelvic limb, popliteal region. 1. N.ischiadicus; 2. N.cutaneus surae caudalis; 3 . N. tibialis; 4. N. fibularis. (147 x $60 \mathrm{~mm}$ 300DPI) 
branch to the biceps femoris, semimembranosus, and semitendinosus muscles. This muscular branch then gave rise to a thin branch to the $\mathrm{m}$. abductor cruris caudalis. The N.ishiadicus continued caudally and medially to the $\mathrm{m}$. biceps femoris and laterally to the m. semimembranosus. The N.ischiadicus gave off a slender the cutaneus surae caudalis nerve the near the head of the fibula. The N.cutaneous surae caudalis distally and divided into two branches. One of the branches ramified into the calcaneus tendon. Another branch crossed the lateral surface of the foot and innervated the skin over the tarsus and metatarsus. The $\mathrm{N}$. ischiadicus divided into the Nn. fibularis communis and tibialis, which supply the muscles of the lower leg, near the knee in the lower third of the femur.

$\mathbf{N}$ fibularis communis (Fig. 4), passed along the medial surface of the $\mathrm{m}$. biceps femoris to the lateral surface of the lateral head of the $\mathrm{m}$. gastrocnemius. On theright side, the average diameter was $1.25 \pm 0.12 \mathrm{~mm}$, and on the left side was $1.20 \pm 0.23 \mathrm{~mm}$. It then coursed distally between the $\mathrm{mm}$. fibularis longus and extensor digitorum longus. Later, the fibularis communis nerve divided into the fibularis superficialis and fibularis profundus nerves.

N. fibularis superficialis (Fig. 4a) ran distally covered by the fibularis longus muscle, in the distal half of the tibia, along the lateral edge of the extensor digitorum longus muscle, to the flexor side of the tarsal joint. N.fibularis superficialis innervated fibularis longus and fibularis brevis muscles. Near the ankle region, it ran close to the surface and sent small branches to the ankle. Later it divided into the lateral and medial branches. The medial branch was thicker than the lateral branch and it gave rise to the Nn.
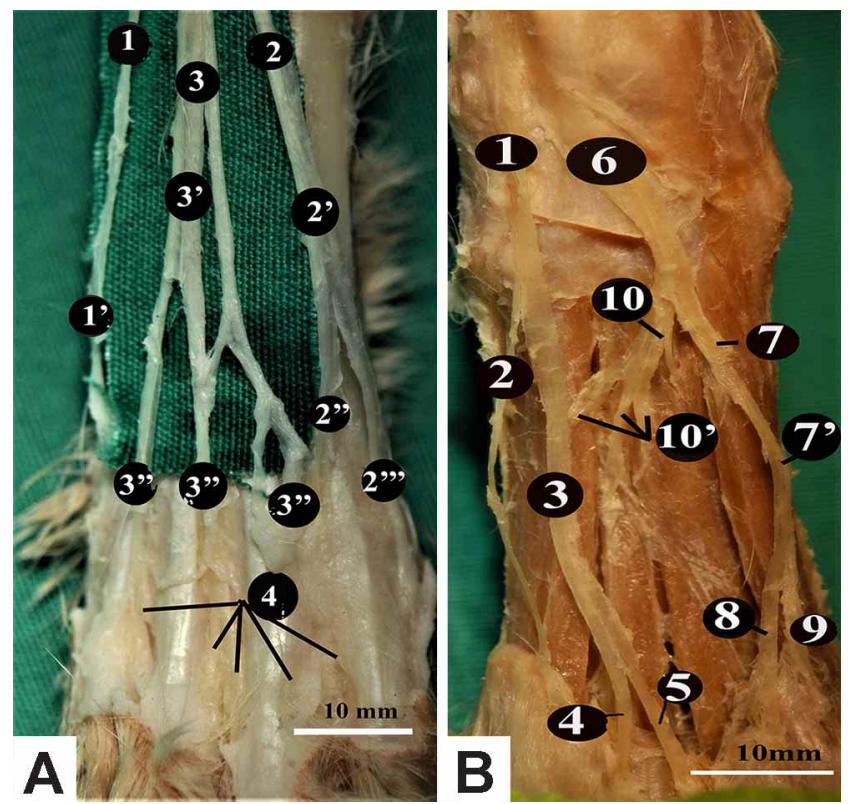

digitalis dorsalis II abaxialis, digitalis dorsalis communis II and III. The lateral branch gave rise to the $\mathrm{N}$. digitalis dorsalis $\mathrm{V}$ abaxialis and then it continued as the Nn. digitalis dorsalis communis II, III, and IV. These nerves divided into the two dorsal proper digital nerves at the level metacarpophalangeal joint.

N. fibularis profundus (Fig. 4a) descended distally between the mm.tibialis cranialis and extensor digitorum longus. It then ran distally, accompanying the cranial tibial artery and across the $\mathrm{m}$. tibialis cranialis. It gave off a thin branch to the $\mathrm{m}$. tibialis cranialis and later gave off branches to the $\mathrm{m}$. extensor digitorum brevis, and fourth and fifth digits.

The N. tibialis was thicker than the N. fibularis communis and descended distally between the $\mathrm{mm}$. flexor digitorum superficialis and gastrocnemius. On the right side, the average diameter was $1.85 \pm 0.12 \mathrm{~mm}$, and on the left side the average diameter was $1.90 \pm 0.23 \mathrm{~mm}$.

The N. tibialis gave off branches innervating the $\mathrm{mm}$. gastrocnemius, flexor digitorum superficialis, profundus, tibialis caudalis, soleus, digitorum brevis, digitorum longus and the tarsal joint. The tibial nerve passed around the medial side of the tarsal joint to the plantar surface of the foot and divided into the plantaris lateralis and plantaris medialis nerves.

$N$. plantaris lateralis (Fig. 4b) was divided into the deep and superficial plantar nerves at the level of the tarsometatarsal joint. The superficial branch gave rise to the $\mathrm{N}$. digitalis plantaris $\mathrm{V}$ abaxialis and then continued as the $\mathrm{N}$. digitalis plantaris communis IV. The $\mathrm{N}$. digitalis plantaris

Fig. 4. A. Dorsal view of the N. fibularis communis and its branches of the left pes. 1.The medial branch of N.fibularis superficialis for the second digit; 1 '. N.digitalis dorsalis communis II; 2 . The lateral branch of N.fibularis superficialis for the fifth digit; 2 '. N.digitalis dorsalis; 2" and 2". Nn. digitalis dorsalis communis IIIV; 3 . The deep branch of the fibular nerve; 3 '. Dorsal Nn. metatarsei dorsales II-IV; 3 ". Nn. digitalis dorsalis communis II-IV of the deep branch; 4. Nn. digitalis dorsalis proprius II-V axial/abaxial. B. Plantar view of deep plantar nerves of the right pes. Metatarsi and metatarsophalangeal regions. 1.N. plantaris medialis; 2. N.digitalis plantaris II abaxialis (medial); 3. Metatarsal plantar nerve of medial branch; 4. and 5. N. digitalis plantaris communis II and III; 6. N. plantaris lateralis; 7. Superficial (lateral) branch of the N. plantaris lateralis; $7^{\prime}$. N. metatarsei plantaris lateralis; 8. N. digitalis plantaris communis IV; 9 . N. digitalis plantaris lateralis $\mathrm{V}$ abaxialis (lateral); 10. The deep branch of the N. plantaris lateralis; 10'. Metatarsei plantares nerves II, III, IV of deep branch of the N. plantaris lateralis (91x $87 \mathrm{~mm} 300 \mathrm{DPI})$ 
communis IV divided into the plantar proper digital nerves and terminated on the apposed surface of the digits. The deep branch gave off the Nn. metatarsei plantares II, III, IV, and the skin on the plantar surface of the metatarsus. The Nn. metatarsei plantares joined the Nn. medial plantar metatarsei near the metatarsophalangeal joint to form the $\mathrm{N}$. digitalis plantaris communis IV. The $\mathrm{N}$. digitalis plantaris communis III, IV, and V divided into the axial and abaxial plantar proper digital nerves, which innervated the skin of contiguous digits and its plantar surface.

$N$. plantaris medialis (Fig. 4b) was thicker than the lateral plantar nerve. It divided into two superficial plantar metatarsal nerves. Each of these nerves divided into the remaining medial and lateral plantar digital nerves. These branches are summarized as follows: In Van cats, the $\mathrm{N}$. plantaris medialis first gave rise to the $\mathrm{N}$. digitalis plantaris II abaxialis and was later separated from the metatarsal plantar nerves II, III, and IV at the proximal end of the metatarsus. The Nn. metatarsei plantares innervated the $\mathrm{mm}$. quadratus plantae (m. flexor accessorius), interflexorii, and lumbricales. The N. digitalis plantaris communis II, III, and IV were formed by the junction of the medial and lateral metatarsal digital nerves at or near the distal end of the metatarsus. The $\mathrm{N}$. digitalis plantaris communis IV divided into the N.digitalis plantaris proprius IV abaxialis and n.dgitalis plantaris proprius $\mathrm{V}$ axialis.

N. cutaneus femoris caudalis (Fig. 3b) arose from the S2 and S3 nerves. On the right side, the average diameter was $0.47 \pm 0.12 \mathrm{~mm}$, and on the left side the average diameter was $0.45 \pm 0.24 \mathrm{~mm}$. It accompanied the pudendal nerve and ran parallel to the sacrotuberal ligament. The $\mathrm{N}$. cutaneous femoris caudalis gave rise to the perineal branch. Later it ran across the biceps femoris, semimembranosus, and semitendinosus muscles and terminated at the skin on the caudal proximal part on the m. popliteus.

Although nn. clunium caudales is a branch of n.cutaneus femoris caudalis, it originated from ventral branches of the S2 and S3 spinal nerves. The lateral branch of Nn.clunium caudales, while moving towards the lateral side of the m.biceps femoris, the medial branch is also distributed on the skin of the proximal part of the m.semitendinosus.

N. pudendus (Fig. 2b,3a) originated from the ventral branches of the S1, S2, and S3. The branches of S1 were fragile and took a communicating branch from the $\mathrm{N}$.ischiadicus. On the right side, the average diameter was $0.41 \pm 0.10 \mathrm{~mm}$, and on the left side the average diameter was $0.37 \pm 0.19 \mathrm{~mm}$. The pudendus nerve ran caudally then divided into the superficial and deep perineal nerves (Fig.
$2 b)$. The superficial perineal branch terminated in the ventral perineal region, the vulva, and the skin of the anus. The deep perineal branch coursed toward the vagina and gave off two small branches innervating the perineal muscles and the clitoris.

Nn. rectales caudales (Fig. 3a) originated from the back of the sacral nerves. In two cats it originated from $\mathrm{S} 1, \mathrm{~S} 2$, and $\mathrm{S} 3$, and in the three cats. it originated from S2 and S3. On the right side, the average diameter was $0.57 \pm 0.11 \mathrm{~mm}$, and on the left side the average diameter was $0.55 \pm 0.05$ $\mathrm{mm}$. The Nn. rectales caudales continued across the lateral surface of the rectum and terminated in the vesica urinaria, the rectum, and the perineal region.

\section{DISCUSSION}

In this study, the formation and distribution of the lumbosacral plexus in the pelvic limbs of Van cats. In transplantation, the most common donor nerves are the saphenous and tibial nerves. For example, these nerves are used after a tumor excision, after a severe injury to a nerve, plexus injuries, or in resolving a primary nerve function deficiency (such as with the radial nerve or the ischiatic nerve). Regeneration speed is $1 \mathrm{~mm}$ per day however, regeneration power in the nerve cell is rapidly depleted after four months. Therefore, the anatomy of the lumbosacral plexus has a vital role in veterinary medicine (Jaggy \& Platt, 2010).

This study demonstrates the specific anatomy of the lumbosacral plexus in the Van cat. According to the literature, the ventral branches of last four lumbar and S1 (Ghoshal), L4 through S2 (Dyce et al.) or L3-S3 spinal nerves (Bennett, 1976), or have been reported as a part of the lumbosacral plexus. In this study, the lumbosacral plexus was observed to occur at the junction of the ventral branches of the L4-S3.

It is formed by the ventral branch of n.ilioinguinalis L3 in carnivores (Dursun; König et al., 2015). Also, according to Dursun, N.genitofemoralis originates from the ventral branch of L3 or L3-L4 (König et al.). It is formed by the ventral branch of n.ilioinguinalis L3 in carnivores (Dursun; König et al.). According to our findings, it was seen that n.ilioinguinalis consisted of the ventral branch of L3 in all cadavers, and the N.genitofemoralis consisted of only the ventral branches of L4 in all cadavers.

N.cutaneus femoris lateralis originates from the ventral branch of the L4th nerve and gives branches to the lumbar muscles (König et al.). In this study, it was observed 
that it originated from L4-L5 in four cadavers and from L4 in one cadaver. It was also found that it did not give branches to the lumbar muscles.

The $\mathrm{N}$. gluteus cranialis is formed by ventral branches of the spinal nerves L6-L7 (Ghoshal), L7 (Barone \& Simoens, 2010) or L6-L7-S1 (Crouch, 1969) and it separates the $\mathrm{m}$. piriformis, $\mathrm{m}$. tensor fasciae latae and the deep and middle muscles (McClure et al., 1973) or the m. tensor fasciae latae and $\mathrm{m}$. gluteus medius (Crouch). The findings in this study were in line with the literature; the N. gluteus cranialis originated from the ventral branch of the L6-L7$\mathrm{S} 1$, and it terminated in the gluteus medius, gluteus profundus, and tensor fasciae latae muscles.

In the literature, it has been reported that the $\mathrm{N}$. gluteus caudalis originates from the ventral branches of the L6-L7 and S1 (Crouch; Ghoshal) or S1th and S2th nerves (Barone \& Simoens). In this study seen that N.gluteus cranial originated from the ventral branches of the L6, L7 and S1 $(40 \%)$ and S1, S2 (60\%) spinal nerves. This nerve innervated the $\mathrm{m}$. gluteus superficialis and cranial part of the biceps femoris and gluteofemoralis muscles.

In cats, the N. pudendus originates from the ventral branches of either the S2-S3 (Ghoshal; Reighard \& Jennings, 1963) or S1-S3 (Dyce et al.). In this study, the pudendal nerve was composed of the ventral branches of the S1-S3 nerves and divided into the deep and superficial perineal branches. The superficial perineal branch terminated in the ventral perineal region, vulva, and the skin of the anus. The deep perineal branch terminated in the caudal part of the vesica urinaria, perineal muscles, and the $\mathrm{mm}$. sartorius, quadriceps femoris, gracilis and pectineus, the cutaneous region of the medial surface of the thigh, articulatio genus, tarsus, and paw (Dursun; Skerritt \& McLelland, 1984). The findings in this study were in line with the literature; the $\mathrm{N}$. pudendus originated from the ventral branches of the L4, L5, andL6 (40 \%) as reported by Dursun, and L5-L6 (60\%) as reported by Crouch and Ghoshal, and it terminated in the muscles and skin as mentioned above. According to Müller, the N.femoralis gives rise to a sturdy branch that innervates the mm. psoas minor and iliopsoas. In this study, the N.femoralis gave rise to a branch that innervated the $\mathrm{m}$. psoas minor and did not give rise to a branch to the m. iliopsoas.

According to Müller, The N. obturatorius originates from the ventral branches of L5-L6 can receive fibers from $\mathrm{L} 4$, and divides after passing through the foramen obturatum on its cranial edge. In this study, the N. obturatorius was formed by the ventral branches of the L6-L7. As reported by Müller, the N. obturatorius also spread to pectineus, gracilis, adductor longus, adductor magnus adductor brevis and obturatorius externus. However, it did not receive any branches from the L4 spinal nerves.

Most of the literature reports that the N.femoralis originates from L5-L6 (Crouch; Ghoshal) or L4-L6 (Dursun), and divides into quadriceps muscle group. As reported by the authors, it was observed that it originated from the ventral branches L4-L6 spinal nerves and gave branches to the quadriceps femoris, sartorius, pectineus, gracilis muscles.

According to the literature, the N.ischiadicus originates from L6, L7, and S1 (Kumar, 2015) L5, L6, L7, and S1 (Jaggy \& Platt), the lumbosacral plexus, S1st and by a branch from the $\mathrm{S} 2$ th spinal nerves (McClure et al.; Barone \& Simoens), L6 - L7 and the first two sacral nerves Pierrard (1972) or L6, L7, S1, and S2 (Bennett), L6 or L7 Guimarães et al. (2006), L7, and S1-S2 (Dursun). According to Müller, in 5 cats, N.ischiadicus takes a connecting branch from N.pudendus and gives a branch to the guadriceps muscles. In this study, it was determined that N.ischiadicus originated as reported by Kumar and Müller gave branches to biceps femoris, caudal part of semitendinosus, cranial part of semimembranosus, quadratus femoris, gemelli, biceps femoris, abductor cruris caudalis, and obturatorius internus muscles. The quadriceps femoris muscles did not take any branches from either the ischiadicus nerve or the pudendal nerve. According to Roos \& Vollmerhaus (2005), N. tibialis is the stronger of the two nerves emerging from the ischiatic nerve. Immediately after its formation, it caudally gives rise to the $\mathrm{N}$. cutaneus surae caudalis that runs laterally to the skin on the calcaneus bone and to the plantar surface of the paw. At the tarsal joint, the N. tibialis passes the medial tubercle and divides into the Nn. plantaris medialis and plantaris lateralis. In this study, the ischiatic nerve was the thickest nerve. In the beginning, it gave rise to the branch of the $\mathrm{N}$. cutaneus surae lateralis.

As Roos \& Vollmerhaus reported, the Nn. plantaris lateralis and plantaris medialis were divided into two branches just below the tarsal joint. Nn. digitales communes ve $\mathrm{Nn}$. digitales plantares proprii divided into branches. N.digitalis plantaris medialis 2 nd-4th digits, N.digitalis plantaris lateralis in the 4th and 5th digits terminated. According to our findings, N.plantaris lateralis gave branches to III, IV, and $\mathrm{V}$ digits.

Kumar reported that, in cats, the nn. rectales caudales orginated from the n.pudendus. In Van cats, this nerve originated from ventral branches of S1-S3 or S2, S3 nerves. According to Dursun, the N.pudendus is originated from the ventral branch of the S3th spinal nerve. We observed that the N.pudendus consist of the ventral branches of the S1-S3 nerves. 


\section{CONCLUSION}

The information on the origin and distribution of the nerves that make up the lumbosacral plexus in cats varies widely in the literature. Ischiatic nerve complications are common in pelvic and hind leg trauma of cats and dogs and in nerve injuries and tumors of the nerves. Therefore, it is clinically vital to know the locations of nerves and the innervated muscles. In Van cats, the nerves forming the lumbosacral plexus and their distributions were examined. The lumbosacral plexus was formed by the ventral branches of the L4-S3 spinal nerves. N.genitofemoralis consisted of only the ventral branches of L4 in all cadavers. N.femoralis did not give rise to a branch to the m. iliopsoas. N.plantaris lateralis was found to give a branch to the 3th finger. The quadriceps femoris muscles did not take any branches from either the ischiadicus nerve or the pudendal nerve. The obturator nerve did not receive any branches from the L4 spinal nerves. There was no branch to the skin from the caudal gluteal nerve. The thinnest nerve was the pudendal nerve.

NUR, I. H.; PÉREZ, W.; KÖNIG, H. E. \& LINTON, A. Origen y distribución de la anatomía del plexo lumbosacro en gatos Van. Int. J.Morphol., 39(3):848-857, 2021.

RESUMEN: En esta investigación se estudió la inervación de los miembros pélvicos del gato Van. Los orígenes de los nervios, los músculos inervados y los diámetros de los nervios son mostrados en una tabla. En el estudio se utilizaron cinco cadáveres de gatos. En cuatro gatosel nervio pudendo se originaba a partir de los nervios espinales S1-S2. El nervio femoral consistió en los ramos ventrales de los nervios lumbares quinto y sexto. El nervio isquiático estaba compuesto por los nervios espinales sexto y séptimo lumbar (L6-L7) y S1 en todos los cadáveres. El nervio isquiático era el ramo más grueso del plexo sacro (el diámetro medio del lado derecho medía de 3,31 $\pm 0,27 \mathrm{~mm}$ y el diámetro medio izquierdo $3,28 \pm 0,29 \mathrm{~mm}$ ). El plexo lumbosacro estaba formado por los ramos ventrales de los nervios espinales L4-S3. N. genitofemoralis constaba solo de las ramas ventrales de L4 en todos los cadáveres. $\mathrm{N}$. femoralis no dio lugar a un ramo a la m. iliopsoas. Los músculos del cuádriceps femoral no tomaron ningún ramo ni del nervio isquiático ni del nervio pudendo. El nervio obturador no recibió ramos de los nervios espinales L4. No existían ramos a la piel desde el nervio glúteo caudal. El nervio más delgado fue el nervio pudendo. Debido a la escasez de estudios sobre el plexo lumbosacro de los gatos, este estudio completará un vacío en el campo de la anatomía veterinaria.

PALABRAS CLAVE: Felidae; Plaexus lumbosacro; Sistema nervioso periférico; Miembro pélvico.

\section{REFERENCES}

Ates, C. T. Investigation of the Morphological and Physiological Properties of the Distribution of Single-Eye Van Cat. Ph.D. Thesis. Van, The Institute of Health Sciences, Van Yüzüncü Yil University, 2000.

Barone, R. \& Simoens, P. Anatomie Comparée des Mammifères Domestiques: Tome 7. Neurologie II, Système Nerveux Périphérique, Glandes Endocrines, Esthésiologie. Paris, Vigot Freres, 2010.

Bennett, D. \& Vaughan, L. C. The use of muscle relocation techniques in the treatment of peripheral nerve injuries in dogs and cats. $J$. Small Anim. Pract., 17(2):99-108, 1976.

Bennett, D. An anatomical and histological study of the sciatic nerve, relating to peripheral nerve injuries in the dog and cat. J. Small Anim. Pract., 17(6):379-86, 1976.

Cak, B. Turkish van cat and turkish angora cat: a review. J. Agric. Sci. Technol. A, 7:151-9, 2017.

Crouch, J. E. Text-Atlas of Cat Anatomy. Philadelphia, Lea \& Febiger, 1969.

Curtis, D. W. \& da Costa, R. C. Practical Guide to Canine and Feline Neurology. 3rd ed. New Delhi, Wiley Blackwell, 2015.

Dursun, N. Veteriner Anatomi III. Ankara, Medisan Yayınevi, 2000.

Dyce, K. M.; Sack, W. O. \& Wensing, C. J. G. Textbook of Veterinary Anatomy. 4th ed. Philadelphia, PA: Sanders, Elsevier, 2000.

Ghoshal, N. G. The lumbosacral plexus (plexus lumbosacralis) of the cat (Felis domestica). Anat. Anz., 131(3):272-9,1972.

Guimarães, G. C.; Machado, M. R. F.; Santos, A. L. Q.; Vieira, L. G.; de Souza, A. G.; Silva, J. M. M. \& Kaminish, P. S. Origem e distribuição do nervo isquiático no gato doméstico (Felis catus domesticus, Linnaeus, 1758). Biosci. J., 21(1):189-95, 2006.

International Committee on Veterinary Gross Anatomical Nomenclature (ICVGAN). Nomina Anatomica Veterinaria. 6th ed. Hanover, International Committee on Veterinary Gross Anatomical Nomenclature, The Editorial Committee, 2017.

Jaggy, A. \& Platt, S. R. Small Animal Neurology. An Illustrated Text. Hannover, Schlütersche, 2010.

König, H. E.; Liebich, H. G. \& Bragulla, H. Veterinary Anatomy of Domestic Mammals. Textbook and Colour Atlas. 6th ed. Stuttgart, Schattauer, 2015.

Kumar, M. S. A. Clinically Oriented Anatomy of the Dog and Cat. 2nd ed. Ronkonkoma (N.Y.), Linus Learning, 2015.

Lamont, L. A. \& Lemke, K. A. The effects of medetomidine on radial nerve blockade with mepivacaine in dogs. Vet. Anaesth. Analg., 35(1):62-8, 2008.

Maierl, J. \& Liebich, H. G. Investigations on the postnatal development of the macroscopic proportions and the topographic anatomy of the feline spinal cord. Anat. Histol. Embryol., 27(6):375-9, 1998.

McClure, R. C.; Dallman, M. J. \& Garrett, P. D. Cat Anatomy. An Atlas, Text and Dissection Guide. Philadelphia (PA), Lea \& Febiger, 1973.

Müller, S. R. Makroskopisch-anatomische Untrsuchungen Zum Plexus Lumbosacralis Der Katze. Inaugural-Dissertation zur Erlangung der tiermedizinischen Doktorwürde der Tierärztlichen. München, Fakultät der Ludwig-Maximilians-Universität München. 1986.

Nur, I. H. \& Arı, H. H. A macroanatomic and subgross investigation on the arterial vascularization of the thoracic limb in the Van cat. J. Fac. Vet. Med. Univ. Yuzuncu Yil., 11:93-103, 2000.

Nur, I'. H.; Keles, H., \& Pérez, W. Origin and distribution of the brachial plexus of the Van cats. Anat. Histol. Embryol., 49(2):2519, 2020. 
Pierrard, J. Anatomie Appligee des Carnivores Domestiques Chien et Chat. Paris, Maloine, 1972.

Rasmussen, L. M.; Lipowitz, A. J. \& Graham, L. F. Controlled, clinical trial assessing saphenous, tibial and common peroneal nerve blocks for the control of perioperative pain following femoro-tibial joint surgery in the nonchondrodystrophoid dog. Vet. Anaesth. Analg., 33(1):49-61, 2006.

Reighard, J. H. \& Jennings, H. S. Anatomy of the Cat. 3rd ed. New York, Henry Hold and Company, 1963.

Roberts, S. Ultrasonographic guidance in pediatric regional anesthesia. Part 2: techniques. Paediatr. Anaesth., 16(11):111224, 2006.

Roos, H. \& Vollmerhaus, B. Konstruktionsprinzipien an der Vorderund Hinterpfote der Hauskatze (Felis catus). 4. Mitteilung: Muskelinnervation und Bewegungsanalyse. Anat. Histol. Embryol., 34(1):2-14, 2005.

Skerritt, G. C. \& McLelland, J. An Introduction to The Functional Anatomy of The Limbs of Domestic Animals. Bristol, Wright, 1984.
Corresponding author:

Ismail Hakkı Nur

Department of Anatomy

Faculty of Veterinary Medicine

Erciyes University

Kayseri

TURKEY

https://orcid.org/0000-0001-7215-8112

E-mail: hnur_55@hotmail.com

Received: 06-12-2020

Accepted: 26-01-2021 